\title{
Two Dimensional (2d) Experimental of Piling up Behind Submerged Break Water
}

\section{Cyril Bernard Rachman*, Bambang Triatmodjo and Nur Yuwono}

Civil and Environmental Engineering Department, Universitas Gadjah Mada, Yogyakarta, Indonesia

*Corresponding author: Cyril Bernard Rachman, Civil and Environmental Engineering Department, Universitas Gadjah Mada, Yogyakarta, Indonesia, Tel: (679) 338 1044; E-mail: cyril.rachman@fnu.ac.fj

Received Date: February 2, 2018; Accepted Date: July 16, 2018; Published Date: 23 July 2018

Copyright: (c) 2018 Rachman CB, et al. This is an open-access article distributed under the terms of the Creative Commons Attribution License, which permits unrestricted use, distribution, and reproduction in any medium, provided the original author and source are credited.

\begin{abstract}
This research was done because of the continuous alert of coastal erosion due to sea level rise and also due to the fact that habitats and living beings will be affected. All these will be affected because of a submerged breakwater structure constructed near the shoreline to reduce the effect of strong waves without disturbing the ocean view.

Further on to this, the study will see whether there are other disadvantages of constructing the submerged breakwater or not. A 2D experimental was done consisting of 60 simulations with four different types of submerged breakwater models heights, and one simulation is using no structure. The results were then recorded to get the piling-up of the runnings for the different structures.

What was found out was that the piling-up is influenced by certain parameters. Those parameters are (1) pilingup is influenced by structure parameter in terms of structure depth, Rc and (2) piling-up also influenced by wave parameters in terms of Period, T. From the study, it is concluded that the influenced of piling-up to wave parameters, Rc is directly proportional and with respect to Period, $T$ the piling-up is inversely proportional.
\end{abstract}

Keywords: Piling-up; Structure parameters; Submerged breakwater; Wave parameters

\section{Introduction}

\section{Background}

As one of the biggest archipelagic country in the world, Indonesia possesses a coastal line length of about $54,716 \mathrm{~km}$ and the country also having the second longest coastal line in the world after Canada. Which means having long coastal lines, indicates that more people lives in the coastal line area. With Indonesia the fourth most populated country in the world, a lot of people can be found settling in the areas close to the beach. Recently the beaches and coastline have faced and experienced many problems with regards to erosion and abrasion.

Because of this, a suggested and preferred solution is the application of beach nourishment. Beach Nourishment according to Robert Dean [1].

"Comprises the placement of sediment in the nearshore to advance the shoreline seaward and is usually placed in response to beach erosion which may be naturally or anthropogenically induced. Nourishment with compatible sediment has the advantage of maintaining the beach system in a near natural condition and can provide benefits to biota and upland property, the latter by buffering storm erosion and damage".

In this case it is a process in which sand that has been eroded is being replaced by filling back the sand like in (Figure 1a). However, by doing this, it needs large and enormous amount of sand volume. Therefore in order to reduce the amount of sand volume used, the use of submerged structure using Geotube material is applied in (Figure 1b) In this case the sand is only filled from the structure up to the coastline. Based on (Figure 1) below, it shows the amount of sand volume without the present of structure and with the present of structure. The problem of reducing sand nourishment may be achieved, but another possible problem may arise. Having the presence of submerged structure may as well increase the Mean Sea Level (MSL). Increasing this, could influence and cause the shoreline to retreat [2].

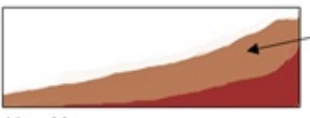

(a) Without Structure

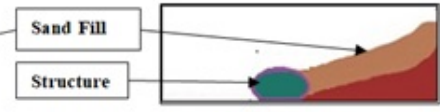

(b) With Structure
Figure 1: Sand nourishment.

\section{Research problem}

As mentioned earlier, the problem is the increased MSL. When MSL increased therefore shoreline retreats as a result cause problems for those living very close to the shoreline. An illustration in Figure 2 shows a possibility of increased MSL and shoreline retreat. 


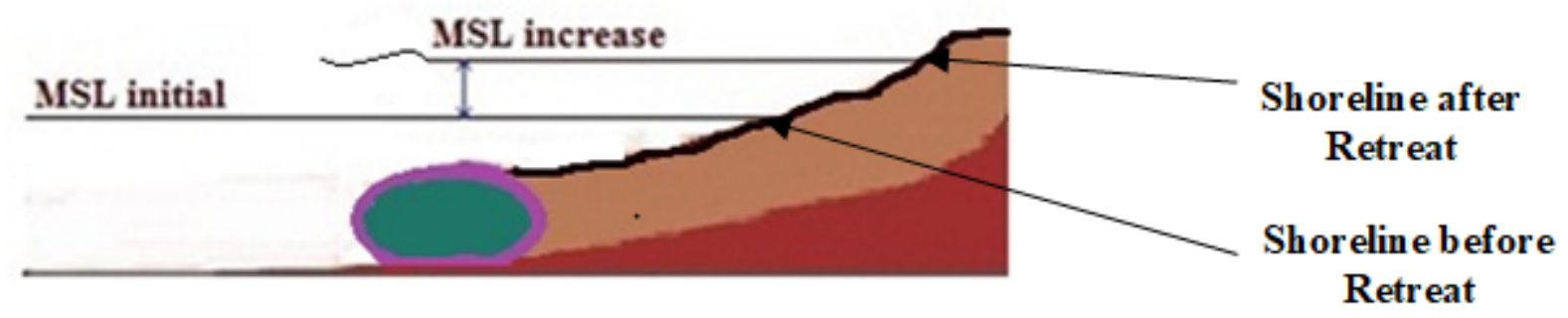

Figure 2: Retreating of shoreline.

\section{Objectives and aims}

The main aims of this research are to investigate the effect of:

- wave parameters influencing to the piling-up, and

- Structure parameters influencing to the piling-up.

\section{Focus}

This research will focus mainly in:

- Regular waves

- Structure located before breaking of the waves

- One type of sand (Krakal of size $0.433 \mathrm{~mm}$ )

- Structure material used is Geotube.

\section{Benefit}

There are many benefits of this research however, one benefit is to be able to determine and know the preferable design for the submerged structure without causing much piling up (increasing of MSL).

\section{Literature Review}

\section{Piling-up}

The pilling-up a phenomenon as described by Diskin is:

"An expression of the quasi-equilibrium reached between the mean rate or water flowing into the protected zone by waves breaking over the low or submerged breakwater, and that of water flowing out of the protected zone as a result of the difference in mean water levels inside and outside. The two flows are unsteady and periodic, having a period, T, equal to that of the wave train" [3].

\section{Previous research by Ruol P, Faedo A and Paris A (2003)}

Aim of the investigation was to evaluate the behavior of this kind of structure in terms of reflection and transmission of incident waves, as well as the study of the wave overtopping phenomenon and the associated increase in the water levels behind the breakwater (water piling-up). The wave-structure interaction was examined by reproducing about 70 irregular wave attacks. In the first part of the study a rubble mound permeable breakwater was analyzed, while in the second part of the research an impermeable plate was placed on the landward slope of the structure, in order to study in more details the complex phenomena of the wave overtopping over the structure and of the seepage through it, also related to the piling-up level at the back of the structure [4].
Previous research by Diskin HM, Vajda M and Amir I (1970)

In his paper, he mentioned that altogether some 190 tests were carried out on the two trapezoidal breakwaters. Plotting the values of the height of piling-up, $\mathrm{Pu}$, against the waveheight, $\mathrm{Ho}$, led to a family of curves for various values of the submergence, S. Again there was considerable scatter about the mean curves. Following a dimensional analysis of the variables involved in the piling-up phenomenon, it was decided to use the wave height, Ho, as a basis for non-dimensional quantities and to plot the relative piling-up $(\mathrm{Pu} / \mathrm{Ho})$ against the relative submergence (S/Ho).

\section{Theory}

\section{Wave theory}

Ocean waves are mostly caused by the action of wind on water. The waves are formed primarily by a complex process of resonance and shearing action, in which waves of differing wave height, length and period are produced and travel in numerous directions. Once formed, ocean waves can travel vast distances, spreading in area and reducing in height, but maintaining wavelength and period.

Airy wave equations derivation: The Airy wave was derived using the concepts of two-dimensional ideal fluid flow. This is a reasonable starting point for ocean waves, which are not greatly influenced by viscosity, surface tension or turbulence. Figure 3 shows a sinusoidal wave of wavelength $\mathrm{L}$, height $\mathrm{H}$ and period $\mathrm{T}$. The variation of surface elevation with time, from the still-water level, is denoted by (referred to as excursion) [5] and given by, $\eta=\frac{H}{2} \operatorname{COS} 2 \pi\left(\frac{x}{L}-\frac{t}{T}\right)$

Where $\mathrm{x}$ is the distance measured along the horizontal axis and $\mathrm{t}$ is time. The wave celerity, c, is given by, $C=\frac{L}{T}$ 


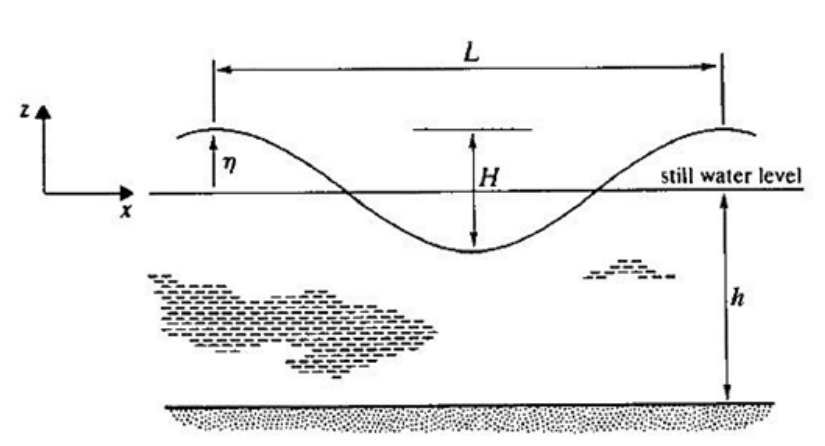

Figure 3: Defination sketch for a sinusoidal wave.

Radiation stress (momentum flux) theory: This theory is used to explain the phenomenon of wave set-up and longshore current generation. Radiation stress is defined as the excess flow of momentum due to the presence of waves (with units of force/unit length). It arises from the orbital motion of individual water particles in the waves. These particle motions produce a net force in the direction of propagation (SXX) and a net force at right angles to the direction of propagation (SYY). The original theory was developed by LonguetHiggins and Stewart [6]. Its application to longshore currents was subsequently developed by Longuet-Higgins [7]. The interested reader is strongly recommended to refer to these papers that are both scientifically elegant and presented in a readable style. Further details may also be found in Horikawa and Komar [8,9].

Shoaling: Consider first a wave front travelling parallel to the seabed contours (i.e. no refraction is taking place). Making the assumption that wave energy is transmitted shoreward without loss due to bed friction or turbulence,

$$
\frac{P}{P_{0}}=1=\frac{E c g}{E_{0}{ }^{c} g_{0}} \text { Substituting } E=\frac{\rho g H^{2}}{8} \text { then } \frac{p}{p_{0}}=1\left(\frac{H}{H_{0}}\right)^{2} \frac{{ }^{c} g}{{ }^{c} g_{0}}
$$

or $\frac{H}{H_{0}}=\left(\frac{{ }^{c} g}{{ }^{c} g_{0}}\right)^{\frac{1}{2}}=K_{S}$

Where Ks is the shoaling coefficient. The shoaling coefficient can be evaluated from the equation for the group wave celerity.

$$
K_{S}=\left(\frac{{ }^{c} g}{{ }^{c} g_{0}}\right)^{\frac{1}{2}}=\left(\frac{\left(\frac{{ } 0}{2}\right)}{\frac{c}{2}\left[\frac{1+2 k h}{\sinh 2 k h}\right]}\right)^{\frac{1}{2}}
$$

The variation of Ks with d/Lo is shown in Figure 4.

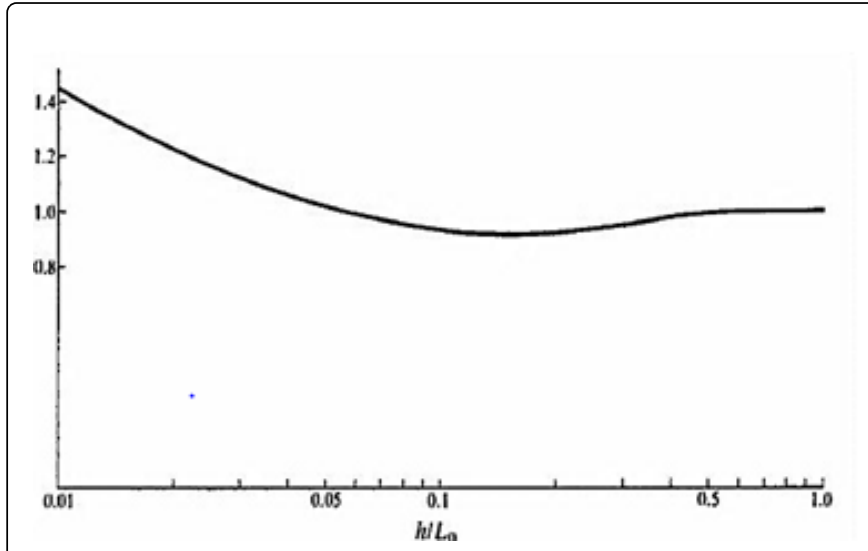

Figure 4: Variation of the shoaling coefficient with depth.

Surf zone processes, wave breaking: There are two criteria which determine when a wave will break. First is a limit to wave steepness and second is a limit on the wave height to water depth ratio. Theoretical limits have been derived from solitary wave theory, which is a single wave with a crest and no trough. Such a wave was first observed by Russell in 1840, being produced by a barge on the Forth and Clyde canal. The two criteria are given by:

Steepness $\mathrm{H} / \mathrm{L}<1 / 7$. This normally limits the height of deep-water waves.

Ratio of height to depth: The breaking index

$\gamma=\mathrm{H} / \mathrm{h}=0.78$

In practice $\gamma$ can vary from about 0.4 to 1.2 depending on beach slope and breaker type in Figure 5.

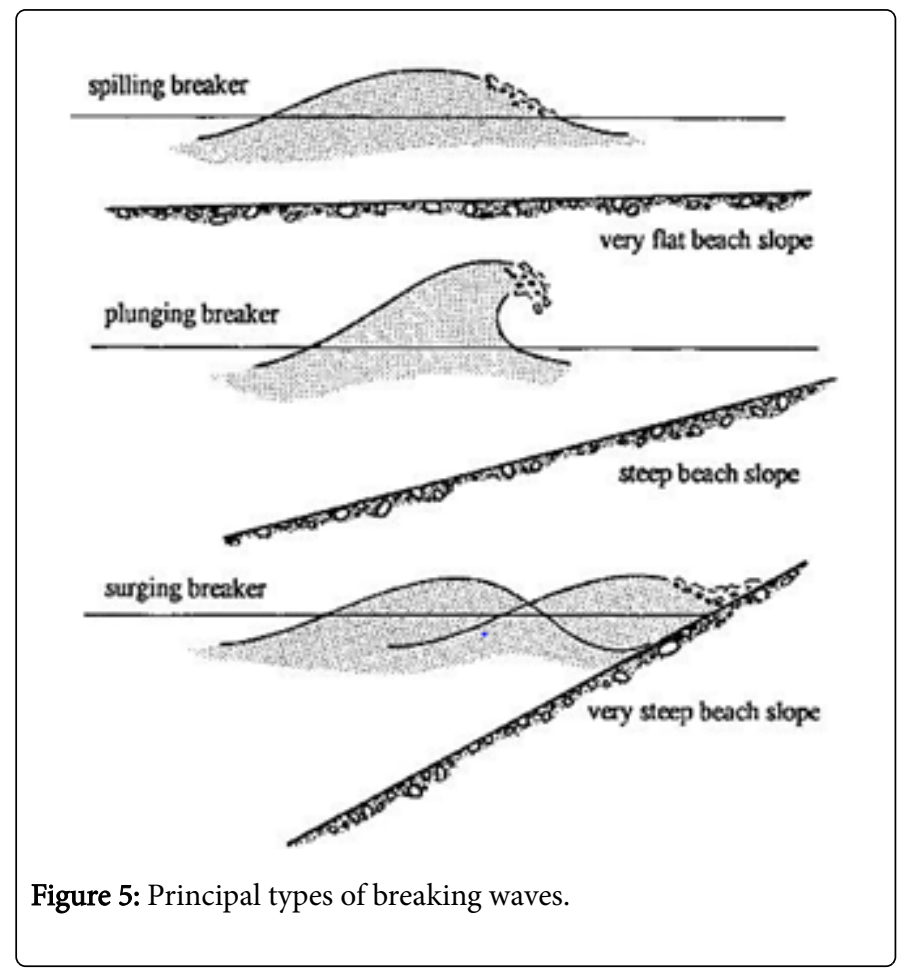


Citation: $\quad$ Rachman CB (2018) Two Dimensional (2d) Experimental of Piling up Behind Submerged Break Water. J Coast Zone Manag 21: 459.

Page 4 of 8

\section{Non-dimensional analysis}

As Yuwono states, to write down the dimensions of the variables defined in the field of hydraulic engineering systems usually used. That is MLT writing dimensions, by using 3-dimensional principal elements: Mass (M), Length (L) and Time (T). The scale of the various variables or parameters described in dimensionless numbers, such as Reynolds number, Froude number and so on. Dimensionless numbers in addition to determining the relationship between the scales is also used to describe the results of the study [10]. Dimensional analysis is used to determine the dimensionless numbers and it is shown or done as follows:-

(1) Basic echelon matrix, (2) Buckingham, (3) Rayleigh, (4) Stepwise, and (5) Langhaar; in this study the analysis of the NDP (nondimensional parameter) used stepwise method dimensional Matrix where the dimensions of the variables used in this study as follows:

$$
\begin{aligned}
& \mathrm{Pu}=\mathrm{L} \text { RC }=\mathrm{L} \quad \mathrm{H}=\mathrm{L} \\
& \mathrm{hs}=\mathrm{L} \mathrm{g}=\mathrm{L} / \mathrm{T} 2 \quad \mathrm{~T}=\mathrm{T}
\end{aligned}
$$

\section{Approach}

\section{Location}

This study is a laboratory research by method of two-dimensional (2-D) physical model test that was conducted at the Laboratory of
Hydraulics and Hydrology, Center for Science and Engineering (PSIT), University of Gadjah Mada, Graphic Street, Yogyakarta, Indonesia.

\section{Simulation}

From the problem that was already described in the objectives as well as in the research methodology, thus, the variable that will be tested in this research could be seen in Figure 6.

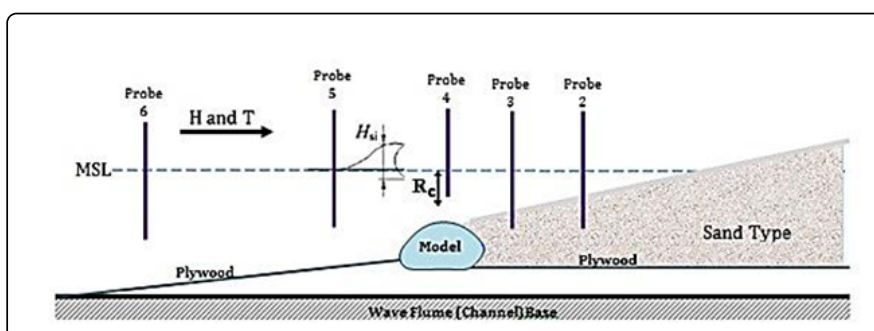

Figure 6: Parameters influencing submerged break water having MSL impact(Also shown is the wave probe position.

According to the objectives to be achieved, in Table 1 presents the

\begin{tabular}{|c|c|c|c|c|c|}
\hline MODEL & Period & Stroke & MODEL & Period & Stroke \\
\hline \multirow{5}{*}{ No Structure } & 1.0 & 6,8 & \multirow{5}{*}{ Structure no.3 } & 1.0 & 6,8 \\
\hline & 1.2 & $4,6,8,10$ & & 1.2 & $4,6,8,10$ \\
\hline & 1.4 & 8,12 & & 1.4 & 8,12 \\
\hline & 1.6 & 8,14 & & 1.6 & 8,14 \\
\hline & 1.8 & 8,16 & & 1.8 & 8,16 \\
\hline \multirow{5}{*}{ Structure 1} & 1.0 & 6,8 & \multirow{5}{*}{ Structure no. 4} & 1.0 & 6,8 \\
\hline & 1.2 & $4,6,8,10$ & & 1.2 & $4,6,8,10$ \\
\hline & 1.4 & 8,12 & & 1.4 & 8,12 \\
\hline & 1.6 & 8,14 & & 1.6 & 8,14 \\
\hline & 1.8 & 8,16 & & 1.8 & 8,16 \\
\hline \multirow{5}{*}{ Structure 2} & 1.0 & 6,8 & No Structure & $\mathrm{Rc}=$ & Zero $(0) \mathrm{cm}$ \\
\hline & 1.2 & $4,6,8,10$ & Structure no.1 & $\mathrm{Rc}=$ & $-1.0 \mathrm{~cm}$ \\
\hline & 1.4 & 8,12 & Structure no.2 & $\mathrm{Rc}=$ & $+2.5 \mathrm{~cm}$ \\
\hline & 1.6 & 8,14 & Structure no. 3 & $\mathrm{Rc}=$ & $+3.5 \mathrm{~cm}$ \\
\hline & 1.8 & 8,16 & Structure no. 4 & $\mathrm{Rc}=$ & $+7.0 \mathrm{~cm}$ \\
\hline
\end{tabular}
simulation design that will be implemented.

Table 1: Simulation design. 
Page 5 of 8

\section{Test Results}

\section{Wave height (Hi), wave period $(\mathrm{T})$ and breakwater depth (Rc)}

The wave height data was obtained from a wave recorder using a probe to measure and record directly into the wave software installed on a computer machine. From the software, all the data are saved in a format of an excel document in which the minimum and maximum heights were recorded. For each submerged breakwater, a record was done for two occasions. The first is when the water is still, then the wave heights were recorded and saved into excel document. Secondly is at the time when the wave is formed, wave height is also recorded.

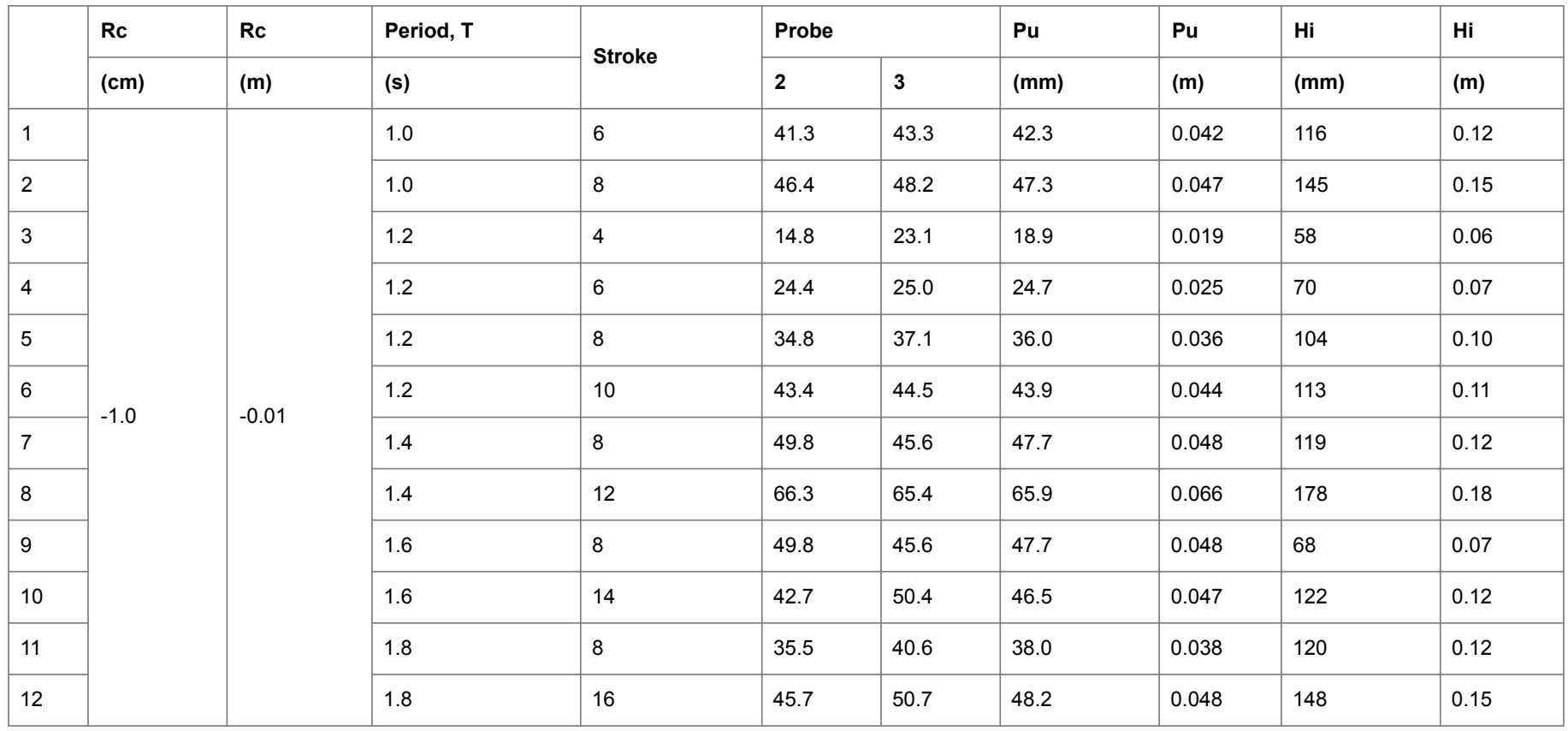

Table 2: Excel data to calculated results.

Table 2 is the result from the recorded excel. This table includes the result for one of the structure $(\mathrm{RC}=-1.0 \mathrm{~cm})$, all the Periods, $\mathrm{T}$, involved in the experiment and all the Stroke, S. From this table, the result of the piling up can be obtained and then wave height (Hi) was calculated.

\section{Analysis}

\section{Influence of wave steepness}

The illustration in Figure 7 below shows that the Piling up (Pu/Ho) parameters have being influenced with the decrease of wave steepness. $\mathrm{Rc} / \mathrm{hs}=-0.04$ is the least steepness however the graph shows the highest piling up impact and the highest steepness of $\mathrm{Rc} / \mathrm{hs}=0.28$ have approximately $30 \%$ of the least steepness of the wave. This shows that having a submerge breakwater with less wave steepness will have more impact towards piling up. Therefore, the results contribute to the understanding that the number of occurrences for lower wave steepness has more influence towards piling up.

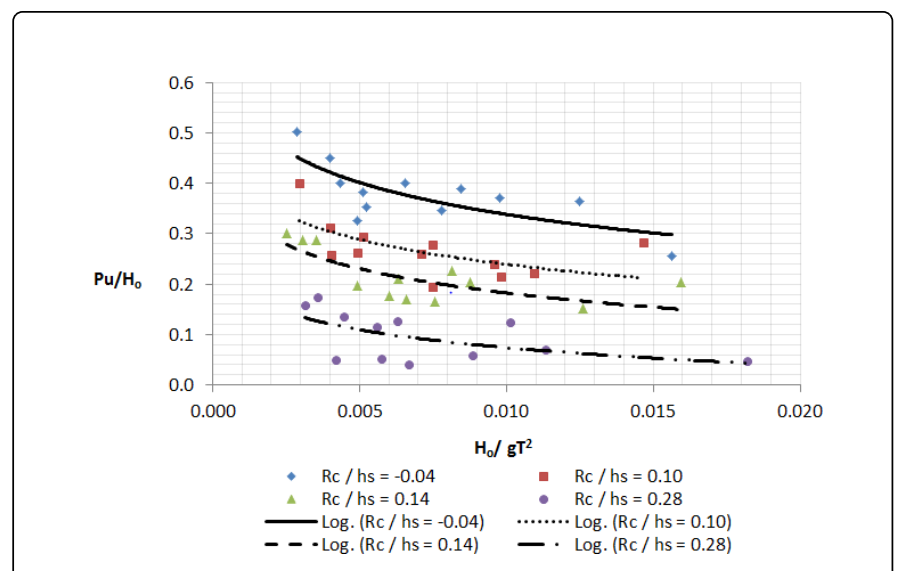

Figure 7: The influence of $\mathrm{Ho} / \mathrm{gT} 2$ to $\mathrm{Pu} / \mathrm{Ho}$ for $\mathrm{Rc} / \mathrm{hs}=-0.04$, $+-0.10,+0.14$, and +0.28 .

Figure 7 shows that Structure $\mathrm{Rc}=-1.0 \mathrm{~cm}$ is represented by a nondimensional analysis of $\mathrm{RC} / \mathrm{hs}=-0.04$. Similarly for Structure $\mathrm{RC}=2.5$ $\mathrm{cm}, \mathrm{RC}=3.5 \mathrm{~cm}$ and $\mathrm{RC}=7.0 \mathrm{~cm}$ are all represented by nondimensional analysis of $\mathrm{RC} / \mathrm{hs}=0.10, \mathrm{RC} / \mathrm{hs}=0.14$, and $\mathrm{RC} / \mathrm{hs}=0.28$.

\section{Influence of structure parameters}

From the Figure 8, the graph clearly illustrates a trend that as Rc/hs decreases then the $\mathrm{Pu} / \mathrm{H}$ decreases also. Moreover, when Period $\mathrm{T}=1.0$ 
$\mathrm{s}, 1.2 \mathrm{~s}, 1.4 \mathrm{~s}, 1.6 \mathrm{~s}$, and $1.8 \mathrm{~s}$, the $\mathrm{Pu} / \mathrm{H}$ increases also as shown in Figure 8. Further to that, when looking at the Structure Parameter ( $\mathrm{Rc} /$ $\mathrm{hs})$, when it increases the depth from $0.025 \mathrm{~m}-0.07 \mathrm{~m}$ depth, there is a reduction of piling up $(\mathrm{Pu} / \mathrm{Ho})$.

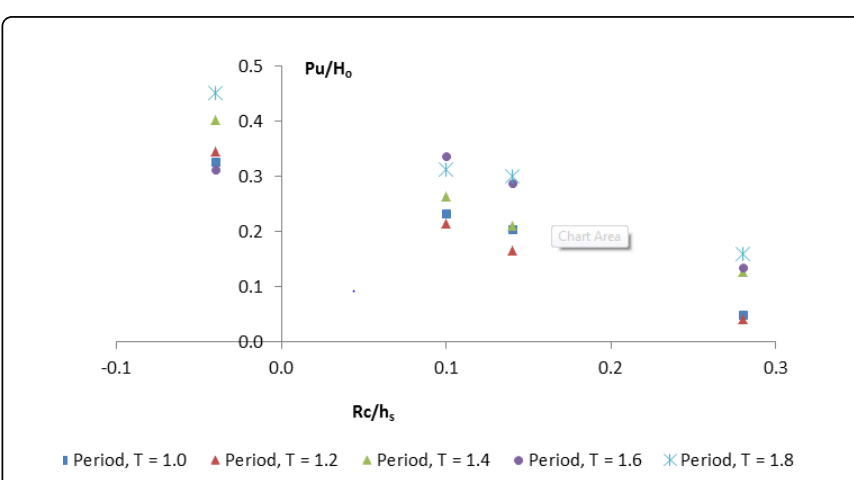

Figure 8: The influence of $\mathrm{rc} / \mathrm{hs}$ to $\mathrm{pu} / \mathrm{ho}$ for periods $(\mathrm{t})=1.0 \mathrm{~s}, 1.2 \mathrm{~s}$, $1.4 \mathrm{~s}, 1.6 \mathrm{~s}$.

When having all $\mathrm{Rc} / \mathrm{hs}=-0.04,0.10,0.14$ and 0.28 , the result is similar to Figure 8 which shows that as the parameter H/gT2 increase, the $\mathrm{Pu} / \mathrm{H}$ decreases. When referring to $\mathrm{Rc} / \mathrm{hs}$ from 0.04 to $-0.28, \mathrm{Pu} / \mathrm{H}$ decreases also. In this case, the greater the $\mathrm{Rc} / \mathrm{hs}$ is, the greater the $\mathrm{Pu} / \mathrm{H}$ and the greater the $\mathrm{H} / \mathrm{gT} 2$, the less the $\mathrm{Pu} / \mathrm{H}$.

\section{Influence of $\mathrm{Rc} / \mathrm{H}$ compared to Diskin's $\mathrm{s} / \mathrm{h}$}

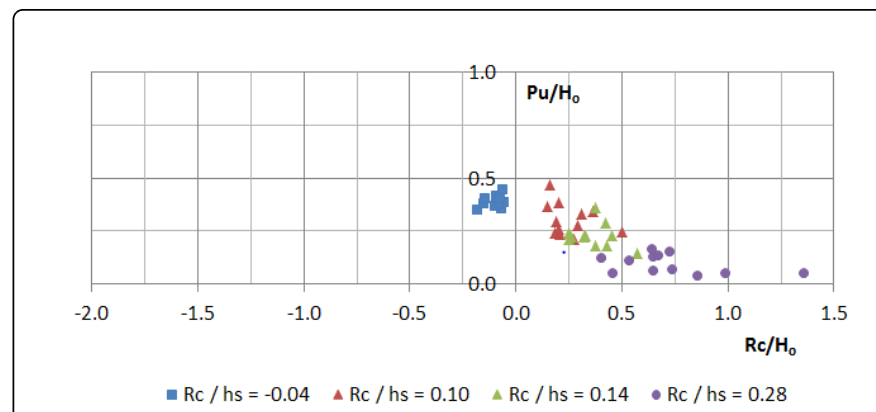

Figure 9: The influence of $\mathrm{Rc} / \mathrm{ho}$ to $\mathrm{pu} / \mathrm{h}$ for $\mathrm{Rc} / \mathrm{hs}=0.04,-0.10$, -0.14 , and -0.28 .

Figure 9 illustrates the graphical outcome of the experiment that was done. Represented from the right to the left is the use of structures of $\mathrm{Rc}=-1.0 \mathrm{~m}$ to $\mathrm{Rc}=7.0 \mathrm{~cm}$. It is clearly noticed that the trend is ascending up towards the left however a maximum cannot be possibly determined because there is no indication of going down towards the left.

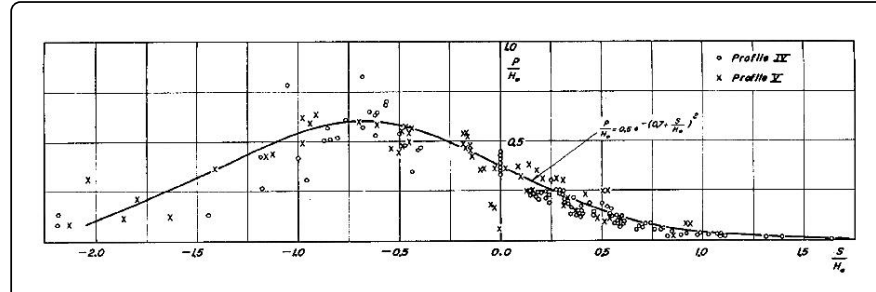

Figure 10: Trapezoidal submerged breakwater experimental results, (Diskin, 1970).

Figure 9 and Figure 10 are of different materials of submerged breakwater. This experimental is using Geotube as the material and Diskin's experiment is using rubble mound trapezoidal submerged breakwater. However, the main concept is to find or investigate the effect of Piling up $\mathrm{Pu} / \mathrm{H}$. Diskin's notation for $\mathrm{Rc}=\mathrm{S}$ which means $\mathrm{Rc} / \mathrm{H}$ for this experiment refers to $\mathrm{S} / \mathrm{H}$ for Diskin's experiment. In Figure 10 it can be seen that the trends keeps on increasing towards the left and reaches it maximum then decrease again still toward the left. However, as mentioned earlier in Figure 9, the increasing towards the left cannot really indicate when it will decrease towards the left. But the important thing is that it can be found out that by combining both Figure 9 and Figure 10, a resultant of Figure 11 can be seen. The result shows that this experiment is within Diskin's Experiment and therefore having a geotube material makes less difference than the rubble mound trapezoidal submerged breakwater. As long as there is a submerged structure of any material, a resultant would be Piling Up.

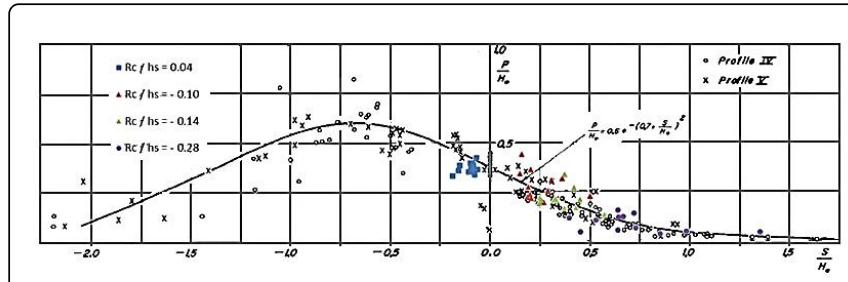

Figure 11: Experimental results for geo tube submerged breakwater comparation with Diskin's results.

From Figure 11, the current experiment data can be found to be located within the range of Diskin's Data and in the Figure, it is between the range of $\mathrm{S} / \mathrm{Ho}=-0.25$ to $\mathrm{S} / \mathrm{Ho}=0.75$. Note that the interpretation that Diskin (1970) use states that as Rc is above the Mean Water Level (MWL), the value becomes negative (-ve) that is $\mathrm{Rc}=-1.0 \mathrm{~cm}$. Therefore when $\mathrm{Rc}$ is below the $\mathrm{MWL}$, the value becomes positive (+ve) for $\mathrm{Rc}=2.5 \mathrm{~cm}, \mathrm{Rc}=3.5 \mathrm{~cm}$ and $\mathrm{Rc}=7.0 \mathrm{~cm}$.

\section{Example Illustration}

Below is an example for application use. 
Page 7 of 8

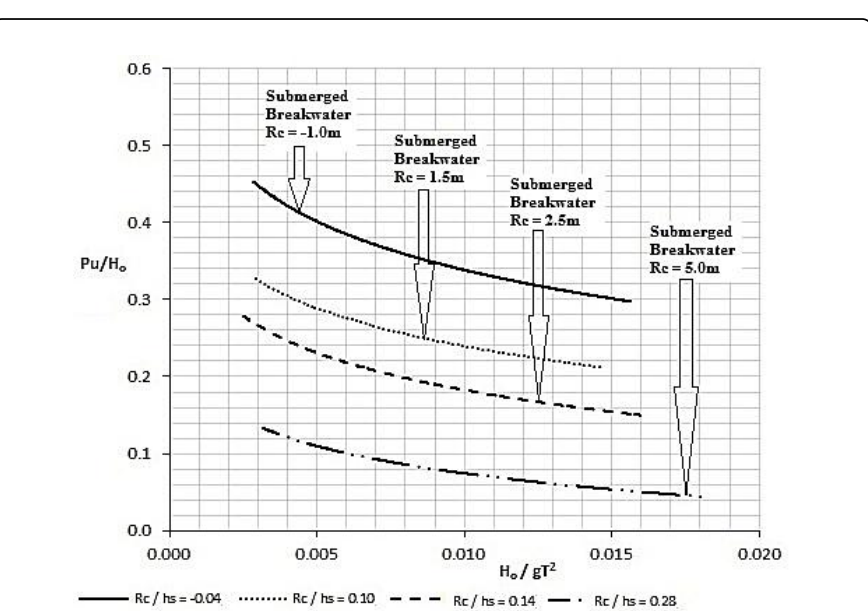

Figure 12: The influence of $\mathrm{Ho} / \mathrm{gT} 2$ to $\mathrm{Pu} / \mathrm{Ho}$.

Source: Analysis Result Data, 2011.

Based on Figure 12 above, in the case of design, for example a given wave period for a particular beach in Indonesia $\mathrm{T}=12.0 \mathrm{~s}$. Then the wave steepness could be found with $\mathrm{g}=9.81 \mathrm{~ms}-2$ and assuming $\mathrm{Ho}=0.081 \mathrm{~m}$. Therefore the wave steepness is calculated as Ho/gT2 $\approx$ 0.0057 . With the use of Figure 12 a structure of RC could be selected, Depending whether the piling-up is acceptable or not $[11,12]$. An illustration as shown below in Figure 13.

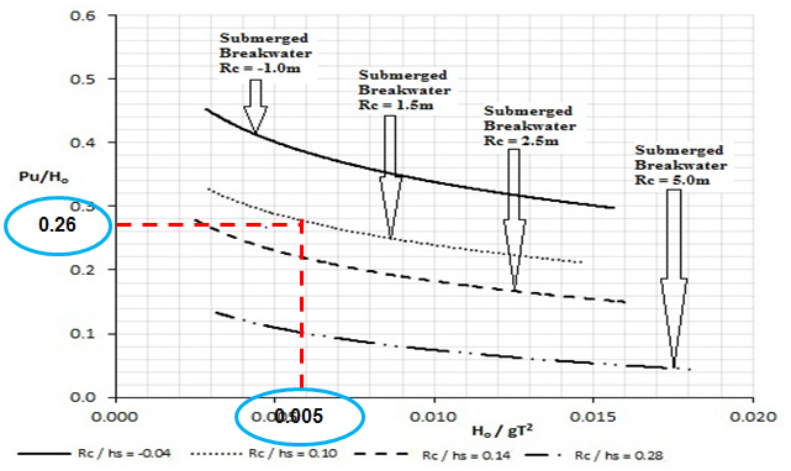

Figure 13: Determining the piling-up.

Given:

$\mathrm{Ho} / \mathrm{gT} 2=(0.081 \mathrm{~m}) /((9.81 \mathrm{~ms}-2) *(12 \mathrm{~s}) 2) \approx 0.0057$

Submerged Structure: $\mathrm{RC}=+1.5 \mathrm{~m}$

Piling-up: $\mathrm{Pu} / \mathrm{Ho}=0.26$ about $26 \%$ (Figure 13)

If somehow other submerged structure were used for the design, then the result could probably be as follows:-

- Submerged Structure: $\mathrm{RC}=-1.0 \mathrm{~m}=$ Piling-up: about 38\% (Figure 13)

- Submerged Structure: $\mathrm{RC}=+2.5 \mathrm{~m}=$ Piling-up: about $22 \%$ (Figure 13)

- Submerged Structure: $\mathrm{RC}=+5.0 \mathrm{~m}=$ Piling-up: about 9\% (Figure 13).

\section{Conclusion}

With the limitation that this research will focus mainly in regular waves, structure located before breaking of the waves, one type of sand (Krakal of size $0.433 \mathrm{~mm}$ ), and structure material used is Geotube, there are some conclusions that can be obtained as follows:-

- It is determined that for the increasing wave parameters (Ho/gT2), the piling up $(\mathrm{Pu})$ decreases.

- For the structure parameters (RC/hs), when it decrease from $\mathrm{RC} /$ $\mathrm{hs}=0.28$ to $\mathrm{RC} / \mathrm{hs}=-0.04$, the piling up $(\mathrm{Pu})$ decrease (Figure 7$)$.

Therefore, a final conclusion based on Figure 13, the higher the wave period, T is then Ho/gT2 will tend to go towards to left. In this case, based again on the Figure 13 the piling up will increase. So with the graphically illustration it can be easier to select which type of submerged breakwater to choose to avoid greater piling up.

In addition, this results should be considered for the impact that a submerged breakwater would have towards the coastline.

\section{Suggestions}

- According to the research, there are some suggestions for further studies:

- It seems that from the result and analysis there is need to add more structures in the case of finding the maximum Piling-up, $\mathrm{Pu}$ in order to compare properly with Diskin's finding.

- Also it is recommended that more research on Piling-up should be carried out in order to know and discover the significant that piling up can cause to the coastal shoreline.

- Lastly but not the least, if the research have a good foundation of results and analysis, this could be used for future design of submerged breakwater.

\section{References}

1. Dean RG, Dalrymple RA (1992) Water Wave Mechanics for Engineers and Scientists. World Scientific Pub, Singapore.

2. Dean RG, Dombrowski MR, Browder AE (1994) Performance of the P.E.P. Reef Installation: Town of Palm Beach, Florida: First Six Months Result. Coastal \& Oceanographic Engineering Department, University of Florida.

3. Diskin MH, Vadja ML, Amir I (1970) Pilling-up behind low and submerged permeable breakwaters. Journal of Waterways and Harbour Division 96: 359-372.

4. Ruol P, Faedo A, Paris A (2004) Physical model study of water piling-up behind low crested structures. Proceedings of 29th International Conference on Coastal Engineering, Lisbon, Portugal, pp: 4165-4177.

5. Airy GB (1845) Tides and waves: Encyclopedia metropolitana. Int J Oceanograph 192: 241-396.

6. Longuet-Higgins MS, Stewart RW (1964) Radiation stresses in water waves: A physical discussion with applications. Deep Sea Res 11: 529562 .

7. Longuet-Higgins MS (1970) Longshore currents generated by obliquely incident sea waves. J Geophys Res 75: 6778-6789.

8. Horikawa K (1978) Coastal Engineering. University of Tokyo Press, Tokyo.

9. Komar PD (1976) Beach Processes and Sedimentation. Prentice-Hall, Englewood Cliffs, NJ, p: 429.

10. Yuwono N (1996) Perencanaan Model Hidraulika. Laboratorium Hidraulika dan Hidrologi, PAU IT UGM, Yogyakarta. 
Citation: $\quad$ Rachman CB (2018) Two Dimensional (2d) Experimental of Piling up Behind Submerged Break Water. J Coast Zone Manag 21: 459. doi:10.4172/2473-3350.1000459

Page 8 of 8

11. Paotonan C (2011) Underwater wave from Geotextile Tube Materia (Geotube) for Protect Artificial Sand Beach. Dissertasi S3, Universitas Gadjah Mada, Yogyakarta.
12. Goda Y (2000) Random Seas and Design of Maritime Structures. 2nd edn. Advanced Series on Ocean Engineering, World Scientific Publishing Co. Pte. Ltd. p: 464. 